\title{
Molecular Species Analysis of Arachidonate Containing Glycerophosphocholines by Tandem Mass Spectrometry
}

\author{
Kathleen Kayganich and Robert C. Murphy \\ National Jewish Center for Immunology and Respiratory Medicine, Denver, Colorado, USA
}

\begin{abstract}
Carboxylate anions arising from collision-induced dissociation (CID) of the $[\mathrm{M}-15]^{-}$ion produced by fast atom bombardment (FAB) of glycerophosphocholine (GPCho) were previously shown to be produced in an abundance ratio of 1:3 for the carboxylic acids esterified at $s n-1$ and $s n-2$, respectively. This observation has been confirmed in a series of 13 synthetic GPCho molecular species. A good correlation was found between the isomeric purity of GPCho molecular species as determined by negative-ion FAB/CID analysis and the isomeric purity of the sn -2 fatty acid using a phospholipase $A_{2}$ assay. Negative-ion FAB mass spectra of several 1-O-alkyl-2-acyl-GPCho molecular species were found to be similar to those of diacyl GPCho. However, the CID spectra from the major high-mass ions are different from those of the diacyl species in that the $[M-15]^{-}$ion yields only one carboxylate anion and the $[\mathrm{M}-86]^{-}$undergoes a neutral loss of the $s n-2$ carboxylic acid as a major decomposition product. These results suggest several rules useful for structural characterization of GPCho molecular species by negative-ion tandem mass spectrometry (MS/MS): (1) For diacyl species, the mass of the two carboxyl anions plus the mass of the GPCho backbone (minus a methyl group) must correspond to the mass of the [M - 15] anion; (2) for diacyl species there is a carboxylate anion ratio approximately 1:3 for the substituents at $s n-1$ and $s n-2$; and (3) for alkylether species, only one fatty acyl group is present, and the difference between the [M-15] ion and the GPCho backbone (minus methyl) plus the fatty acyl group at $s n-2$ corresponds to an alkylether substituent. (4) Assignment of ether-linked molecular species can be made from the $[\mathrm{M}-86]^{-}$ion, which has a strong neutral loss of the $s n-2$ fatty acid.

Analysis of GPCho isolated from human neutrophils by total lipid extraction and normal-phase HPLC was carried out by negative-ion FAB and MS/MS. The major arachidonate-containing molecular species, which comprise only 5\% of total GPCho, were identified by using precursor ion scans for the arachidonate anion, $\mathrm{m} / \mathrm{z}$ 303. Decomposition of identified precursor ions permitted the assignment of those molecular species of GPCho that contain arachidonate at $s n-2$ and identification of the substituent at the $s n-1$ position. These results were compared to previously identified molecular species from human neutrophils. Several minor arachidonate-containing molecular species were tentatively identified. (I Am Soc Mass Spectrom 1991, 2, 45-54)
\end{abstract}

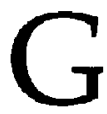
LYCEROPHOSPHOLIPIDS constitute a major fraction of the components of membranes within all mammalian cells [1]. Interest in these molecules has stemmed largely from the biophysical properties they display in separating compartments within cells and defining cellular boundaries as well as their effect on membrane fluidity [2] or adaptations in composition due to temperature change [3]. More recently, however, it has become recognized that phospholipids also serve as precursors of biologically active compounds that play important roles in

Address reprint requests to Robert $C$. Murphy. Pediatrics, Room K929, National Jewish Center for Immunology and Respiratory Medícine, 1400 Jackson Street, Denver, CO 80206. physiological regulation of complex cellular processes such as mediation of cell-cell communication $[4,5]$ and intracellular receptor-signal transduction processes [6]. These regulatory substances are derived from phospholipids, so they are typically termed lipid mediators and fall into three general classes. One category contains the metabolites of arachidonic acid formed by the action of cyclooxygenase resulting in prostaglandins [7] or by action of 5-lipoxygenase resulting in leukotrienes [8]. A second class of lipid mediators are the platelet-activating factor (PAF) molecular species derived from phosphatidylcholines with a long-chain ether substituent at $s n-1$ and a very short chain, typically acetate, at $s n-2$ [9]. Third, diacylglycerols, derived from various phospholipids, 

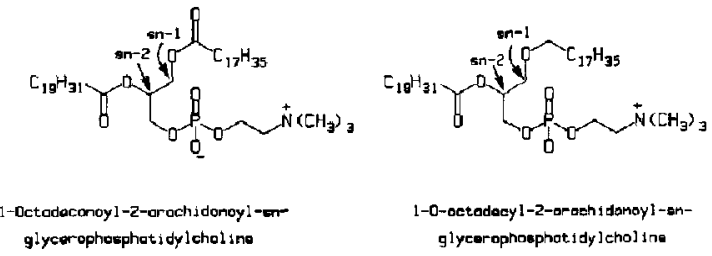

Structure I

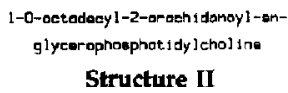

are known to activate protein kinase $C$ and in this way participate in receptor-signal transduction [10].

Whereas a great deal of information has been obtained concerning the biosynthesis of prostaglandins and leukotrienes from arachidonic acid and PAF biosynthesis from lyso-PAF (1-O-alkyl-sn-glycerophosphocholine), we are only beginning to understand the complexities involved in the liberation of free arachidonic acid and lyso-PAF from phospholipid precursors [11]. The various membranes within cells are composed of complex mixtures of glycerophosphocholines (GPCho's). ${ }^{1}$ There are many phospholipid molecular species that may serve as precursors for free arachidonic acid and lyso-PAF. Identification of the exact molecular species of phospholipids and, in particular, arachidonate-containing GPCho's within a cell, has been a challenging analytical endeavor. Structures of two representative arachidonate-containing GI'Cho molecular species, 1-octadecanoyl-2arachidonoyl-GPCho and 1-octadecyl-2-arachidonoylGPCho, are shown here as Structures I and II, respectively.

In 1986, Jensen et al. [12] suggested that fast atom bombardment (FAB) and tandem mass spectrometry (MS/MS) could be effective in identifying molecular species of glycerophospholipids, including GPCho. They used a three-sector mass spectrometer with an electric sector to analyze the product ions following collision-induced decomposition (CID) of negative ions from GPCho. The resolution of this instrument for daughter ions was approximately 100 , which limited to some extent the ability to analyze fatty acyl components of phospholipids that differ by a single double bond. In 1988, Munster and Budzikiewicz [13] confirmed these observations and extended the analysis to 11 molecular species of glycerophosphatidylcholine that differed in fatty acyl groups at $s n-1$ or $s n-2$. The present work extends these reports by addressing the analysis of arachido-

\footnotetext{
${ }^{1}$ Abbreviations used: $s n-1$ and $s n-2$, stereospecifically numbered positions 1 and 2 on the sn-GPCho backbone (also, the identity of the fatty acids in the $s n-1$ and $s n-2$ positions are indicated by the numerical order in which they are written, for example, 16:0e/20:4 GPCho, where 16:0 represents a 16-carbon fatty acid with no double bonds, and 20:4 represents a 20-carbon fatty acid with four double bonds. The lowercase letter following the $s n-1$ fatty acid indicates the type of linkage at $s n-1$, either, $a, e$, or $p$ representing acyl, ether, or vinyl ether, which is commorly referrec to as plasmalogen); PAF, platelet-activating factor; PLA 2 , phospholipase $\mathrm{A}_{2}$; TRIS, tris(hydroxymethyl)-aminomethane; CID, collisioninduced dissociation.
}

nate-containing molecular species and 1-O-alkyl ether phosphatidylcholines. Furthermore, MS/MS with better product ion resolution is used to identify molecular species in a biological extract.

\section{Methods and Materials}

\section{Materials}

Phospholipid molecular species were purchased from Avanti Polar Lipids (Birmingham, AL) or from Sigma Chemical Company (St. Louis, MO). All lipids were used without further purification. Solutions in chloraform were made between 0.25 and $1.0 \mu \mathrm{g} / \mu \mathrm{L}$. Phospholipase $\mathrm{A}_{2}$ (from Crotalus adamanteus) was obtained from Sigma Chemical Company. All other reagents were commercially obtained in the purest grade possible.

\section{Mass Spectrometry}

Mass spectra were obtained on a Finnigan TSQ70B (San Jose, CA) triple-quadrupole mass spectrometer equipped with a saddle-field FAB gun by Ion Tech (Middlesex, England). Xenon was used as the particle source with a typical accelerating potential of $5 \mathrm{kV}$ at 1 $\mathrm{mA}$. Argon was used in the second quadrupole (Q2) collision cell at a pressure of 0.5 mtorr. Collision energy offset $\left(E_{\text {lab }}\right)$ of $30 \mathrm{eV}$ was used to induce dissociations (CID). The instrument was equipped with a conversion dynode, which was set at $12 \mathrm{kV}$ for these experiments. Typically, five product ion scans (from $m / z 150$ up to $20 \mathrm{u}$ higher than the mass of the selected precursor ion, in 2 s) were averaged for each ion decomposed. A precursor ion scan of $m / z 303$ was used to determine the arachidonate-containing molecular specics in the ncutrophil GPCho fraction. Subsequent product ion scans were then obtained for each precursor of $\mathrm{m} / \mathrm{z} 303$.

Isomeric purity ( $X$; mole fraction of specified positional isomer) of GPCho molecular species was calculated from the observed intensity ratio $(R)$ of the $\mathrm{FAB} / \mathrm{MS} / \mathrm{MS}$ carboxylate anions from $s n-1$ and $s n-2$ by using the equation

$$
X=\frac{1}{2}(3-R) /(R+1)
$$

where $R$ is the intensity ratio for $\mathrm{R}_{1} \mathrm{COO}^{-} / \mathrm{R}_{2} \mathrm{COO}^{-}$, and $\mathrm{R}_{2} \mathrm{COO}^{-}$is identified by being more abundant than $\mathrm{R}_{1} \mathrm{COO}^{-}$. This equation was derived by assuming that an absolute carboxylate anion intensity ratio of $1: 3$ would be observed for a pure positional isomer.

\section{Phospholipase $A_{2}$ Assay}

An assay involving the use of phospholipase $A_{2}$ $\left(\mathrm{PLA}_{2}\right)$ was performed to determine the purity of the positional isomer of each synthetic GPCho molecular 
species. Phospholipid, 50-100 $\mu \mathrm{g}$, in $\mathrm{CHCl}_{3}$ solution, was transferred to screw-cap glass tubes and dried under a stream of dry nitrogen at $37^{\circ} \mathrm{C}$, followed by addition of a small volume of diethyl ether, which was reevaporated to remove traces of $\mathrm{CHCl}_{3}$. The residue was reconstituted in $2 \mathrm{~mL}$ of diethyl ether, and a mixture of PLA 2 (100 units in $50 \mu \mathrm{L}$ of TRIS buffer), TRIS buffer ( $100 \mu \mathrm{L}$ of $0.2 \mathrm{M}, \mathrm{pH} 7.5)$, calcium chloride $(40 \mu \mathrm{L}, 0.1 \mathrm{M})$, and distilled water $(210 \mu \mathrm{L})$ was then added to the ether in each tube. The test tubes were sealed with Teflon-lined caps and vortexed continuously for at least $3.5 \mathrm{~h}$ to create inverted micelles, which increase the ether-aqueous interfacial surface area at which the reaction between the substrate and the enzyme occurs. Without separation of layers, the ether was evaporated, and the remaining aqueous layer was acidified with a drop of glacial acetic acid and extracted three times with two volumes of hexane. The hexane-extracted fatty acids were converted to methyl esters with diazomethane.

Fatty acid methyl esters were analyzed by gas chromatography by using flame ionization detection. The detector was heated to $280^{\circ} \mathrm{C}$, and the injector to $250-280^{\circ} \mathrm{C}$. Splitless injection was used with no purge flow for $0.5 \mathrm{~min}$ after injection. The fused-silica capillary column (DB-1, $10 \mathrm{~m} \times 0.25 \mathrm{~mm}$ i.d, $0.25 \mu \mathrm{m}$ film thickness; J \& W Scientific, Rancho Cordova, CA) was operated with helium carrier gas at a head pressure of $7 \mathrm{psi}$. The temperature program was from 120 to 180 ${ }^{\circ} \mathrm{C}$ at $30^{\circ} \mathrm{C} / \mathrm{min}$, then from 180 to $260{ }^{\circ} \mathrm{C}$ at 5 ${ }^{\circ} \mathrm{C} / \mathrm{min}$. Relative peak areas were determined, and areas were converted to mole \% fatty acid using relative response factors [14]. Fatty acid methyl ester identification was confirmed by GC/MS (EI, $70 \mathrm{eV}$ ).

\section{Isolation of Glycerophosphocholine from Neutrophils}

Neutrophils were isolated from human blood as previously described [15]. A total lipid extract of approximately $200 \times 10^{6}$ neutrophils was carried out according to the method of Bligh and Dyer [16] with $20 \mathrm{~mL}$ of $\mathrm{CHCl}_{3} / \mathrm{MeOH}$. Solid butylated hydroxytoluene (25 mg) was added to the chloroform layer to prevent oxidation of the lipids. After removal of the chloroform under vacuum, the extract was reconstituted in mobile phase for normal-phase high-performance liquid chromatography (NP-HPLC) purification. The mobile phase used for the separation of the phospholipid classes consisted of a gradient from $47 \%$ solvent A (hexane/isopropanol; 3/4, v/v) held for $6 \mathrm{~min}$, changing to $100 \%$ solvent $B$ (hexane/ isopropanol/water; $3 / 4 / 0.7, \mathrm{v} / \mathrm{v} / \mathrm{v}$ ) over a 20 -min period. The flow rate was $1 \mathrm{~mL} / \mathrm{min}$. The $\mathrm{NP}-\mathrm{HPLC}$ column used was a $4.6 \mathrm{~mm} \times 25 \mathrm{~cm}$ silica column with $5 \mu \mathrm{m}$ particle size from Alltech Applied Science (State College, PA). The elution of the phospholipid classes was monitored with a UV detector set to monitor absorption at $206 \mathrm{~nm}$.

\section{Results}

Three abundant high-mass negative iuns are produced upon FAB ionization of diacyl GPCho molecular species as noted by others [12, 13]. These anions correspond nominally to $[\mathrm{M}-15]$ (loss of $\mathrm{CH}_{3}$ ), [M - 60] (loss of $\mathrm{HN}\left(\mathrm{CH}_{3}\right)_{3}$ ), and $[\mathrm{M}-86]$ (loss of $\left.\mathrm{CH}_{2} \mathrm{CHN}\left(\mathrm{CH}_{3}\right)_{3}\right)$, as seen for the molecular species 1-octadecanoyl-2-arachidonoyl-sn-glycerophosphatidylcholine (I) in Figure 1a. Previous work in this laboratory has indicated that formation of the demethylated ion $[M-15]$ involves the initial formation of a matrix-phospholipid adduct ion that also decomposes to the two additional high-mass ions [17]. This accounts for the fact that neither the $[M-60]$ nor the $[\mathrm{M}-86]$ ions are produced upon collisional activation of the $[M-15]$ ion directly (see Figure 1b). However, it is also possible that some of the $[M-60]$ ion is produced through $\beta$-elimination (Hoffman reaction) of the phospholipid in the condensed phase, induced by the xenon atom beam. When each of these major high-mass ions is collisionally activated, abundant carboxylate anions are observed. Decomposition of the $[M-15]$ (Figure $1 b$ ) ion as well as the $[M-60]$ (Figure 1c) ion yields two carboxylate anions $(m / z 283$ and 303 ) in a relative abundance ratio of $1: 3$. These $\mathrm{m} / \mathrm{z}$ values correspond to the stearate and arachidonate carboxylate anions. Decomposition of the [M 86] (Figure 1d) ion leads also to the generation of these two carboxylate anions, but with an abundance ratio opposite to that observed for the decompositions of $[M-15]$ and $[M-60]$, that is, $3: 1$ for $s n-1: s n-$ 2 . In addition, significant ions from [M - 86] are observed at $m / z 419$ and 437 , corresponding to the loss of $\mathrm{C}_{18} \mathrm{H}_{29}-\mathrm{CH}=\mathrm{C}=\mathrm{O}$ and $\mathrm{C}_{19} \mathrm{H}_{31}-\mathrm{COOH}$, respectively (i.e., loss of the alkyl ketene and the carboxylic acid moiety esterified at $s n-2$ ).

The CID spectra of several commercially available diacyl GPCho molecular species are summarized in Table 1. As noted previously [12], the abundance of the carboxylate anions resulting from the fatty acid esterified at the $s n-1$ position relative to the $s n-2$ position should be in a ratio of $1: 3$ in the CID of $[\mathrm{M}-15]^{-}$. This ratio has been thought to reflect the relative rates of formation of the carboxylate anions by the CID process. However, for most of the molecular species measured in Table 1 , the ratio of the abundances of $s n-1: s n-2$ carboxylate anions was significantly higher than 1:3. One possible reason for this difference was the presence of positional isomers of the molecular species in these commercial, synthetic phospholipids. Other explanations for the observed ratios may include the use of low energy for the CID process, the effect of unsaturation in fatty acyl groups, or the effect of the chain length of each acyl substituent on the decomposition.

To assess the isomeric purity of the fatty acyl groups at $s n-2$ of the phospholipid species, specific hydrol- 


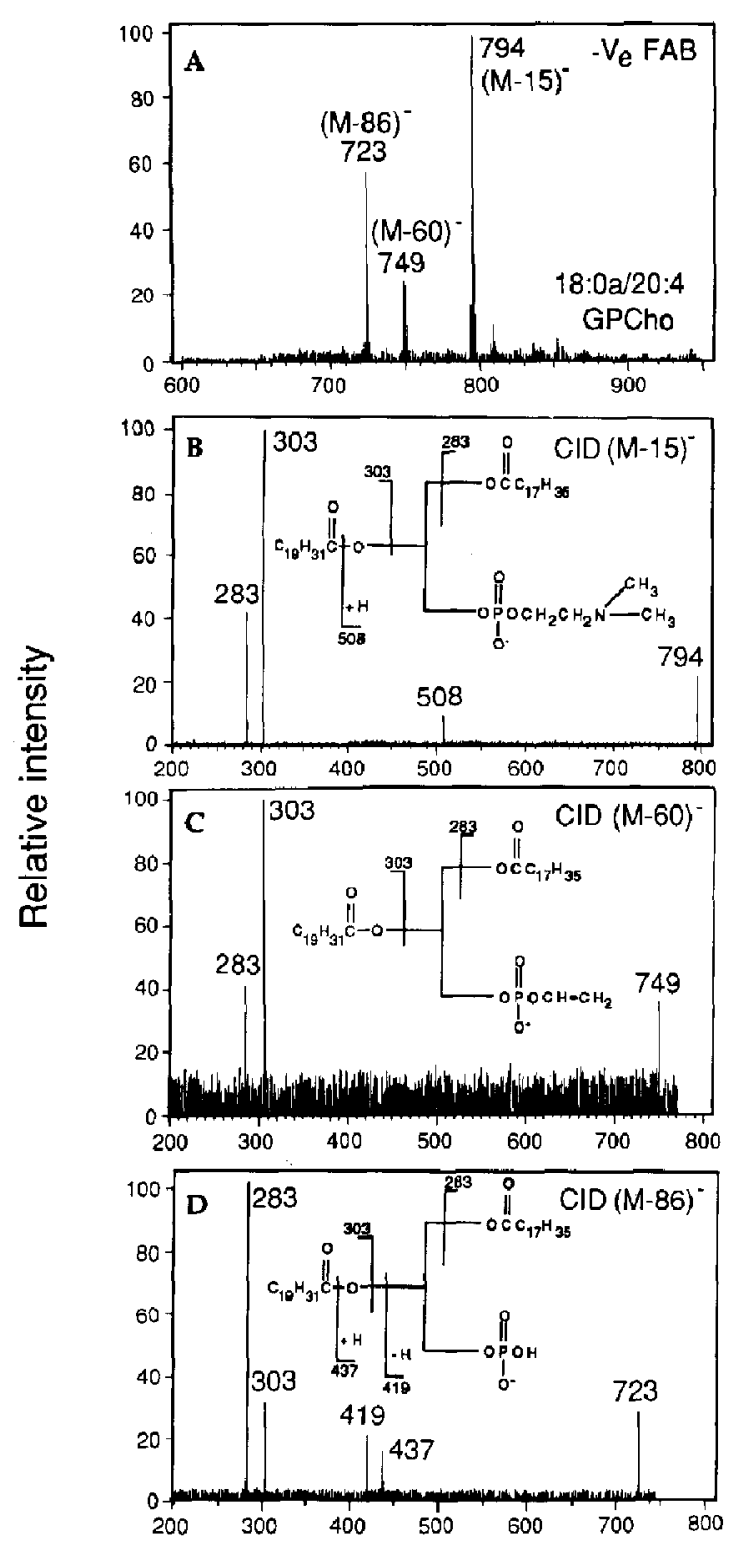

$\mathrm{m} / \mathrm{z}$

Figure 1. Fast atom bombardment mass spectrometry of 1-octadecanoyl-2-arachidonoyl-sn-glycerophosphatidylcholine: (a) High-mass negative ions produced by $\mathrm{FAB} ; m / z 794,749$, and 723, correspond to $\left[\mathrm{M}-\mathrm{CH}_{3}\right]^{-},\left[\mathrm{M}-\mathrm{HN}\left(\mathrm{CH}_{3}\right)_{3}\right]^{-}$, and $[\mathrm{M}-$ $\left.\mathrm{CH}_{2}=\mathrm{CHN}\left(\mathrm{CH}_{3}\right)_{3}\right]^{-}$, respectively; (b) $\mathrm{CID} \mathrm{MS} / \mathrm{MS}$ of $[\mathrm{M}-$ $\left.\mathrm{CH}_{3}\right]^{-}$; (c) $\mathrm{CID}$ of $\left[\mathrm{M}-\mathrm{HN}\left(\mathrm{CH}_{3}\right)_{3}\right]^{-}$; (d) $\mathrm{CID}$ of $[\mathrm{M}-$ $\left.\mathrm{CH}_{2}=\mathrm{CHN}\left(\mathrm{CH}_{3}\right)_{3}\right]^{-}$. CID conditions were 0.5 mtorr argon and $E_{\text {lab }}$ of $30 \mathrm{eV}$.

ysis was carried out with the enzyme PLA 2 [18]. Liberated fatty acids were methylated and then analyzed by gas chromatography. The measured isomeric purity (as determined by PLA $_{2}$ assay) is compared with that based upon the observed ratio of the carboxylate anions obtained by negative FAB/MS/MS (CID of $[\mathrm{M}-15])$ in Figure 2. The mass spectrometric results were calculated, assuming that the expected positional isomer would result in a 1:3 abundance ratio of carboxylate anions for $s n-1: s n-2$ from CID of the $[M-15]$ ions. Similar results for the calculated purity were obtained using 1:3 abundance ratios for $[M-60]$ ions and 3:1 for the $[M-86]$ ions.

Several of the synthetic phospholipids contained significant amounts of positional isomers. There was a significant linear correlation $(r=0.87 ; p=0.0001)$ between the measured purity of molecular species by mass spectrometry and the purity of the molecular species as assessed by enzymatic hydrolysis (Figure 2). It is of interest to point out that although the slope of this line was close to unity, the intercept was nonzero $(y=0.73 x+0.36)$. Nevertheless, a reasonable estimate of the $s n-1: s n-2$ fatty acyl substitution can be obtained from direct mass spectrometric analysis by CID of the [M - 15] anions with assessment of the ratios of carboxylate anion intensities.

In addition to the diacyl molecular species of GPCho, several 1- $O$-alkyl-2-acyl molecular species were examined. These mass spectra are tabulated in Table 2. The high-mass ions generated by FAB/MS/MS are analogous to those previously observed and reported for diacyl species of GPCho, as can be seen in Figure $3 a$, which shows FAB spectra of 1-O-octadecyl-2arachidonoyl GPCho (II). However, only one carboxylate anion $(\mathrm{m} / \mathrm{z} 303)$ is produced upon CID of the $[M-15]$ (Figure 3b) and [M - 60] (Figure 3c) ions from 18:0e/20:4-GPCho, because there is only one fatty acid ester moiety (arachidonoyl) in this molecule. Cleavage of the 1-O-alkyl bond is not observed during the FAB process or after CID of source ions. However, CID of the [M -86$](m / z 709$, Figure $3 d)$ ion results in a rather intense ion corresponding to loss of the $\mathrm{R}_{2} \mathrm{COOH}(\mathrm{m} / \mathrm{z} 405)$ and only a minor ion corresponding to the carboxylate anion at $s n-2(\mathrm{~m} / \mathrm{z}$ 303, Figure 3d). The appearance of these ions is substantially different from those observed for decompositions of the corresponding ion in the diacyl species. The neutral loss of the $\mathrm{R}_{2} \mathrm{COOH}$ further confirms the identity of the molecular species as a 1-O-alkyl-2-acylGPCho as well as the exact assignment of the fatty acyl group at $s n-2$.

\section{Arachidonoyl Molecular Species in the Human Neutrophil}

Analysis of the human neutrophil GPCho by FAB/MS reveals a complex mixture of molecular species as shown in Figure 4a. Those ions that occur at even masses can correspond to $[\mathbf{M}-15]^{-}$, whereas the ions at odd masses correspond to either the $[\mathrm{M}-60]^{-}$ or $[\mathrm{M}-86]^{-}$species. From the abundances of the [M - 15] anions, the major molecular species of GPCho in the human neutrophil are evident. The ions represented by $m / z 770,744$, and 730 likely correspond to the major diacyl and alkylacyl species, 
Table 1. Relative intensities of the product ions from the fatty acyl groups following $\mathrm{CID}$ of the precursor ions [M - 15], [M - 60], and [M - 86] from 1,2-diacyl-GPCho molecular species ${ }^{\mathrm{a}}$

\begin{tabular}{|c|c|c|c|c|c|c|}
\hline \multirow{2}{*}{$\begin{array}{l}\text { Precursor: } \\
\text { Products } \\
\text { Molecular } \\
\text { species }\end{array}$} & \multirow{2}{*}{ MW } & \multirow{2}{*}{$\frac{[\mathrm{M}-15]^{-}}{\mathrm{R}_{1} \mathrm{COO}^{-} / \mathrm{R}_{2} \mathrm{COO}}$} & \multirow{2}{*}{$\frac{[M-60]^{-}}{\mathrm{R}_{1} \mathrm{COO}^{-} / \mathrm{R}_{2} \mathrm{COO}^{-}}$} & \multicolumn{3}{|c|}{$[M-86]^{-}$} \\
\hline & & & & 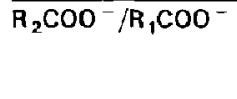 & $-R_{2}=\mathrm{C}=0 / \mathrm{R}_{1} \mathrm{COO}^{-}$ & $-\mathrm{R}_{2} \mathrm{COOH} / \mathrm{R}_{1} \mathrm{COO}^{-}$ \\
\hline $16: 0 a / 14: 0$ & 705 & 0.70 & 0.65 & 0.58 & 0.20 & 0.25 \\
\hline $14: 0 a / 16: 0$ & 705 & 0.48 & 0.46 & 0.62 & 0.23 & 0.33 \\
\hline $14: 0 a / 18: 0$ & 733 & 0.45 & 0.47 & 0.80 & 0.20 & 0.35 \\
\hline $18: 0 a / 14: 0$ & 733 & 0.78 & 0.70 & 0.50 & 0.18 & 0.22 \\
\hline 16:0a/18:2 & 757 & 0.34 & 0.37 & 0.46 & 0.26 & 0.36 \\
\hline $16: 0 a / 18: 1$ & 759 & 0.45 & 0.43 & 0.54 & 0.20 & 0.30 \\
\hline $18: 1 a / 16: 0$ & 759 & 0.34 & 0.37 & 0.34 & 0.15 & 0.25 \\
\hline $16: 0 a / 18: 0$ & 761 & 0.47 & 0.53 & 0.68 & 0.22 & 0.35 \\
\hline $18: 0 a / 16: 0$ & 761 & 0.70 & 0.68 & 0.57 & 0.18 & 0.30 \\
\hline $18: 0 a / 18: 1$ & 787 & 0.38 & 0.35 & 0.38 & 0.18 & 0.20 \\
\hline $18: 1 a / 18: 0$ & 787 & 0.33 & 0.41 & 0.38 & 0.20 & 0.19 \\
\hline $16: 0 a / 20: 4$ & 781 & 0.56 & 0.56 & 0.42 & 0.31 & 0.49 \\
\hline $18: 0 a / 20: 4$ & 809 & 0.43 & 0.52 & 0.33 & 0.15 & 0.20 \\
\hline
\end{tabular}

a Synthetic phospholipids commercially available. Indicated molecular species may be impure owing to acyl migration during synthesis.

${ }^{b} R_{1} \mathrm{COO}^{-}$, fatty acyl group esterified at sn $-1 ; R_{2} \mathrm{COO}-$, fatty acyl group esterified at sn $-2 ;-R_{2}=C=0$, loss af sn -2 acyl group as ketene from the $[M-86]$ ion; $-R_{2} C_{0 O H}$ loss of sn -2 carboxylic acid from the $[M-86]$ ion.

whereas the ions at $m / z 699,673$, and 659 then correspond to $[M-86]$ of these molecular species. It is difficult to uniquely assign an odd-mass ion, because a mass difference of only 26 between $[M-86]$ and $[\mathrm{M}-60]$ is the same mass difference as is ex-

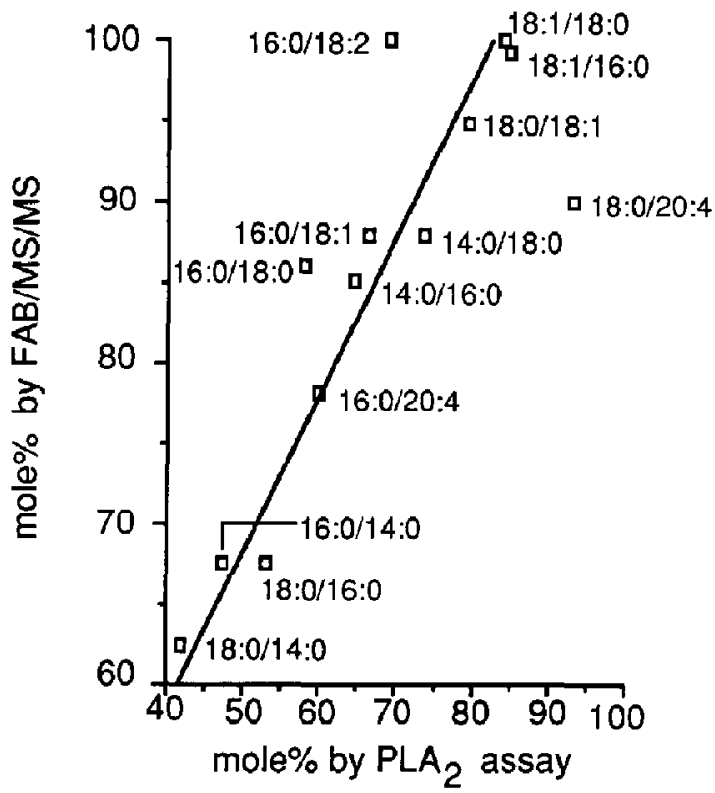

Figure 2. Comparison of the mole fractions of GPCho positional isomers in commercial synthetic GPCho molecular species as determined by negative FAB/CID and by PLA $A_{2}$ analysis of the $s n-2$ fatty acid(s). Mole fractions calculated using the FAB/CID data assumed that CID analysis of a pure positional isomer would produce carboxylate anions from $s n-1$ and $s n-2$ in an abundance ratio of $1: 3$. pected for an additional two-carbon chain with one more degree of unsaturation, which is typically found for homologous lipids in naturally occurring GPCho extracts.

Precursor ion scans for individual carboxylate anions readily reveal those molecular species that contain the specified fatty acyl group esterified either at $s n-1$ or $s n-2$. For example, Figure $4 b$ and $c$ are precursor scans for $m / z 281$ (oleate) and $m / z 303$ (arachidonate), respectively. The most abundant diacyl-containing molecular species (Figure 4a) appear at $m / z 772$ and 744, which correspond to the dioleoyl and palmitoyl-oleoyl molecular species of GPCho. The example for arachidonic acid (Figure 4c) is interesting in that all of the precursor ions are minor constituents, comprising only 5\% of the total GPCho [19] with $[\mathrm{M}-15]$ anions at $\mathrm{m} / \mathrm{z} 750,752,766,778,780$, 792, 794, and 806. Other minor species that contain arachidonate are also indicated by the precursor scan.

Assignment of structures corresponding to each of these precursors can be accomplished by employing observations made from the MS/MS of [M - 15] anions: (1) For diacyl species, the mass of the two carboxylate anions (from the CID experiment) plus the mass of the GPCho backbone (minus a methyl group) must correspond to the mass of the [M - 15] anion; (2) for diacyl species, there is a carboxylate anion ratio of 1:3 for the substituents at $s n-1$ and $s n-2$; and (3) for alkyl ether species, only one carboxylate anion is produced in the CID experiment, and the difference between the $[M-15]$ ion and the GPCho backbone (minus methyl) plus the carboxylate anion from $s n-2$ corresponds to the $s n-1$ alkyl ether substituent. To obtain information concerning the above points, it is necessary to carry out a product 
Table 2. Tandem mass spectrometry of $[M-15]$ and $[M-86]$ ions generated by FAB of various 1-O-alkyl-2-acyl-GPCho molecular species ${ }^{\mathrm{a}}$

\begin{tabular}{|c|c|c|c|c|c|c|}
\hline \multirow{3}{*}{$\begin{array}{l}\text { Precursor: } \\
\text { Product: } \\
\text { Molecular } \\
\text { species }\end{array}$} & \multicolumn{6}{|c|}{$\%$ Relative abundance ${ }^{b}$} \\
\hline & \multicolumn{3}{|c|}{$[M-15]^{-}$} & \multicolumn{3}{|c|}{$[M-86]^{-}$} \\
\hline & $\mathrm{R}_{2} \mathrm{COO}^{-\mathrm{c}}$ & $-\mathrm{R}_{2} \mathrm{COOH}^{\mathrm{d}}$ & $-\mathrm{A}_{2}=\mathrm{C}=\mathrm{O}^{\circ}$ & $\overline{\mathrm{R}}_{\mathrm{z}} \mathrm{COO}-\mathrm{C}$ & $-\mathrm{R}_{2} \mathrm{COOH}^{\mathrm{d}}$ & $-\mathrm{R}_{2}=\mathrm{C}=\mathrm{O}^{\circ}$ \\
\hline $16: 0 \mathrm{e} / 20: 4$ & 100 & 5 & 12 & 3 & 100 & 17 \\
\hline $18: 0 e / 20: 4^{f}$ & 100 & 0 & 8 & 0 & 100 & 15 \\
\hline $16: 0 \mathrm{e} / 18: 1$ & 100 & 6 & 14 & 3 & 100 & 14 \\
\hline $16: 0 e / 16: 0$ & 100 & 7 & 10 & 0 & 100 & 18 \\
\hline
\end{tabular}

B Synthetic phospholipids commercially available. Indicated molecular species may be impure owing to acyl migration during synthesis.

${ }^{b}$ Normalized to the most abundant product ion for each scan.

${ }^{-} \mathrm{R}_{2} \mathrm{COO}^{-}$, fatty acyl group esterified at sn -2 .

${ }^{d}$ Loss of sn - 2 carbaxylic acid.

Loss of sn - 2 acyl group as ketene.

'Presented as structure II.

scan for those ions identified as containing a unique fatty acyl group. Such a product scan often reveals some complexity in isobaric molecular species within a biological GPCho extract. However, using the above discussed rules, one can obtain a clear estimate of the species present with a reasonable assignment of the substituents at $s n-1$ and $s n-2$. Figure 5a shows the CID spectrum of the ion at $\mathrm{m} / z 794$ corresponding to an arachidonate-containing molecular species identified by the precursor scan shown in Figure $4 c$. If this mass corresponded to an [M - 15] ion for a diacyl species, it would correspond to a total fatty acyl group of 38:4 (where the first number indicates the total number of carbons in both acyl groups and the second number indicates the total number of double bonds in the two hydrocarbon chains). Considering that arachidonate (20:4) would be present, this would leave 18:0 for a second acyl group $(m / z 283)$. In the product ion spectrum of $m / z$ 794, there is a characteristic ratio between $m / z 303$ and $m / z 283$ corresponding to the expected assignment of 18:0a/20:4-GPCho (Figure 5a). However, there is also an ion present at $m / z 279$ in this spectrum, which would correspond to an 18:2 carboxylate anion. Using the above rules, this could arise from a GPCho molecular species having a fatty acyl group of 20:2 corresponding to $m / z 307$, which is present in the appropriate ratio for esterifcation at $5 n-1$ with the 18:2 at $s n-2$. Thus, another molecular species at this mass $(m / z$ 794) is 20:2a/18:2-GPCho. Other minor species revealed by this product ion spectrum are 16:0a/22:4-GPCho from the carboxylate anions at $m / z 331$ and 255 as well as 20:3a/18:1-GPCho and 18:1a/20:3-GPCho from the carboxylate anions at $m / z 281$ and 305. Although the relative abundances of $m / z 255$ and $m / z \quad 331$ are about equal, it is unlikely that the $22: 4 \mathrm{a} / 16: 0$ isomer is present, because the more unsaturated fatty acids are found at $s n-2$ in naturally occurring phospholipid molecular species.

Analysis of other ions following collisional activation revealed alkyl ether or plasmalogen species from the neutrophil extract. Decomposition of $\mathrm{m} / \mathrm{z} 780$ revealed several carboxylate anions, including 16:0, $18: 1,20: 3,20: 4$, and 22:4. If $m / z 780$ corresponds to a diacyl-GPCho [M - 15] anion, then it would contain $37: 4$ for the total acyl groups at $s n-1$ and $s n-2$. Because it is unlikely to have major odd-chain fatty acids in human neutrophils, one would consider that this [M - 15] anion corresponds to alkyl ether molecular species, which would require $38: 4$ for the acyl and alkyl groups present. The ion at $\mathrm{m} / \mathrm{z} 303$ (arachidonate) would then arise from 18:0e/20:4GPCho. If $m / z 780$ corresponded to a diacyl species with 20:4 ( $\mathrm{m} / \mathrm{z} 303)$ and an odd-chain acyl group at sn -1 (17:1), an ion at $m / z 269$ of approximately $30 \%$ abundance would be expected. This, however, is not observed. The ion at $m / z 279$ (linoleic acid, 18:2) suggests $20: 2 \mathrm{e} / 18: 2-\mathrm{GPCh}$ as another isobaric species present at $m / z 780$. However, another possibility for this species would be an alk-1'enyl ether at $s n-1$ (plasmalogen). The other carboxylate anions at $\mathrm{m} / \mathrm{z}$ $255,281,305$, and 331 support the presence of alkyl ether GPCho molecular species for this [M - 15] ion and assignment of minor molecular species 22:4e/16:0-GPCho, 20:3e/18:1-GPCho (or 20:2p/18:1GPCho), 18:1e/20:3-GPCho (or 18:0p/20:3-GPCho), and 16:0e/22:4-GPCho. Table 3 lists the molecular species identified by FAB MS/MS using the approach discussed above with comparison to those previously identified by more traditional techniques [20, 21]. Further evidence for the assignment of ether-linked molecular species can be obtained by study of the CID product ions from the corresponding $[\mathrm{M}-86]^{-}$ion. For example, a minor molecular species indicated by a precursor ion at $m / z 303$ was tentatively identified as 20:1e/20:4 GPCho on the basis of the product ions after CID of $m / z$ 806. This assignment was confirmed by collisional activation of $m / z 735$, which would correspond to the $[M-86]^{-}$ion of $20: 1 e / 20: 4$ GPCho. Collision-induced dissociation of $m / z 735$ produced a major ion at $m / z 431$, corresponding to the neutral loss of arachidonic acid (loss of $304 \mathrm{u}$ ), as would be expected for the $[M-86]^{-}$ion of $20: 1 e / 20: 4$ GPCho. 

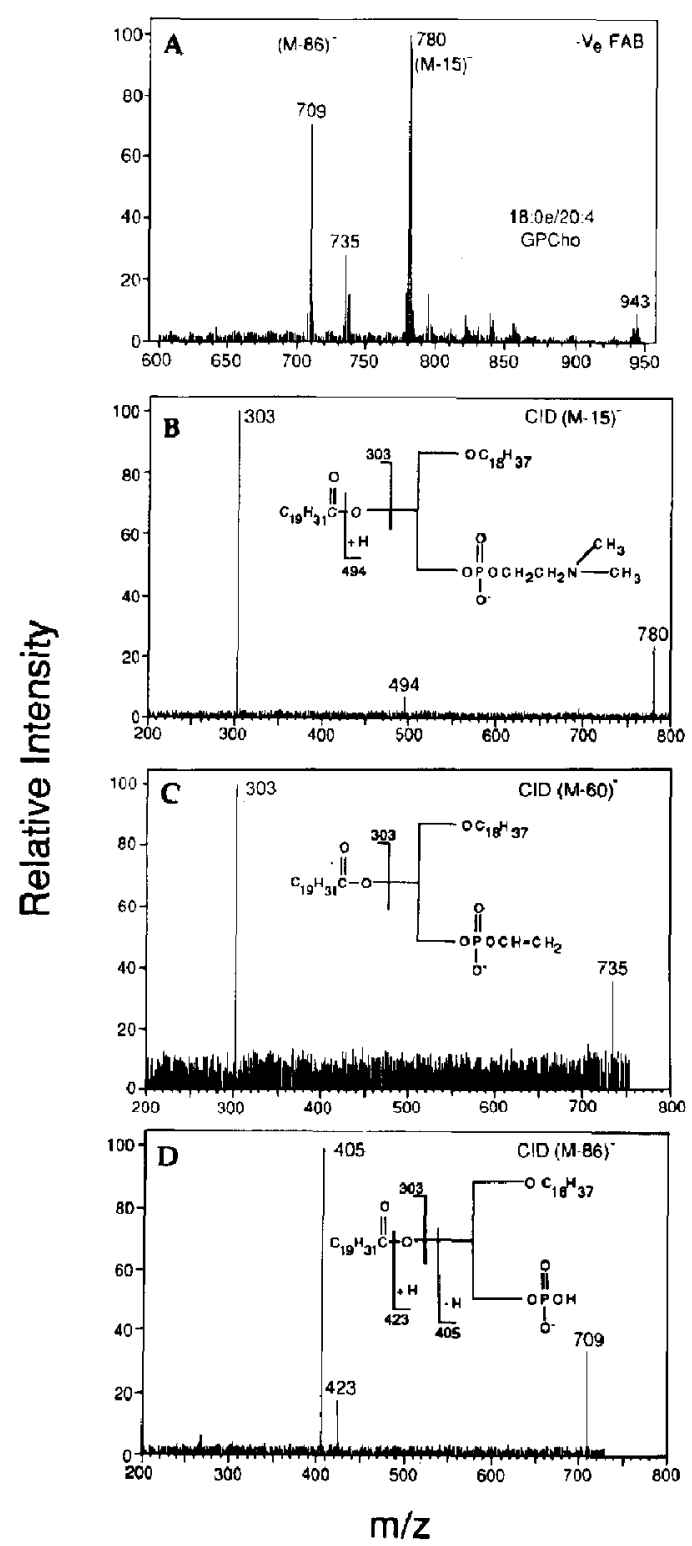

Figure 3. Fast atom bombardment mass spectrometry of 1-Ooctadecyl-2-arachidonoyl-sn-GPCho: (a) High-mass negative ions produced by $F A B ; m / z 780,735$, and 709 , correspond to $[M-$ $\left.\mathrm{CH}_{3}\right]^{-}$, $\left[\mathrm{M}-\mathrm{HN}\left(\mathrm{CH}_{3}\right)_{3}\right]^{-}$, and $\left[\mathrm{M}-\mathrm{CH}_{2}=\mathrm{CHN}\left(\mathrm{CH}_{3}\right)_{3}\right]^{-}$, respectively; (b) CID MS/MS of $\left[\mathrm{M}-\mathrm{CH}_{3}\right]^{-}$; (c) $\mathrm{CID}$ of $[\mathrm{M}-$ $\left.\mathrm{HN}\left(\mathrm{CH}_{3}\right)_{3}\right]^{-}$: (d) $\mathrm{CID}$ of $\left[\mathrm{M}-\mathrm{CH}_{2}=\mathrm{CHN}\left(\mathrm{CH}_{3}\right)_{3}\right]^{-}$with the base peak at $m / z 405$ representing a neutral loss of arachidonic acid from $s n-2$.

\section{Discussion}

A determination of phospholipid molecular species that contain esterified arachidonic acid is necessary for establishing a metabolic relationship between potential phospholipid precursors and arachidonic acid metabolites such as prostaglandins and leukotrienes. It has been suggested that arachidonate, which ultimately is converted into either prostaglandins or leukotrienes, is derived from a unique phospholipid molecular species precursor that contains a 1-O-alkyl substituent at $s n-1$ and arachidonate esterified to $s n-2$ [11]. To investigate the existence of such a unique molecular species precursor, it is important to have the capability of analyzing complex mixtures of phosphatidylcholines that contain arachidonate esterified in different molecular species.

The usual method for the identification of phospholipid molecular species involves stages of separation including normal-phase chromatography to isolate classes of phospholipids on the basis of their polar head groups (phosphatidylcholine, phosphatidylinositol, phosphatidylethanolamine, phosphatidylserine, and phosphatidic acid). Individual molecular species can then be separated on the basis of the fatty acyl groups esterified to $s n-1$ and $s n-2$ by RP-HPLC [22]. Typically, identifications of the exact molecular species are based upon relative retention times. Because the separation of molecular species is based upon the cumulative effects of the hydrophobic nature of the fatty acyl substituents, complete separation of molecular species of phospholipids from natural sources is virtually impossible. Therefore, development of alternative analytical approaches with the ability to identify minor molecular species that might coelute or elute very close to major phospholipid molecular species has become essential. Chemical or enzymatic degradation of separated phospholipid molecular species with subsequent GC analysis of methyl esters is often employed to identify the specific fatty acyl groups, for example, esterified at $s n-2$. However, this process is lengthy and tedious and fails to distinguish between the potential components at $s n-1$ being an 1-O-alkyl ether, 1-O-alk-1'enyl ether, or 1-acyl ester component, because the molecular weight of the intact molecule is not measured. An alternative method has involved the use of phospholipase $C$ [23] or chemical techniques [24] to cleave the polar head group, yielding a diglyceride that can be derivatized into an appropriate derivative for further chromatographic separation. For example, diglycerides can be analyzed by HPLC or mass spectrometric techniques [25].

With the development of alternative methods of mass spectrometric analysis including thermospray and FAB ionization, more direct methods have become feasible for phospholipid analysis. These methods are especially attractive because of the specific information that can be obtained from the mass spectrum and the potential for direct molecular species analysis. Thermospray mass spectrometry has been demonstrated to be useful for online HPLC detection of phospholipid molecular species [26]. However, identity of positional isomers and the assignment of $s n-1$ and $s n-2$ are not afforded by this technique. Fast atom bombardment has been particularly useful for the identification of molecular species of various phospholipid classes [12, 13]. High-mass positive ions $[\mathrm{M}+\mathrm{H}]^{+}$for phosphatidylcholine, phosphatidyleth- 
Figure 4. Negative FAB /MS and MS/MS spectra obtained from the GPCho fraction isolated from human neutrophils. (a) High-mass negative ions produced from the mixture of GPCho molecular species. (b) Precursors of $m / z 281$, corresponding to those ions arising from molecular species that contain esterified oleic acid (18:1). (c) Precursors of $\mathrm{m} / \mathrm{z}$ 303, corresponding to those ions arising from molecular species that contain esterified arachidonic acid (20:4).

anolamine, and phosphatidylserine, indicating the molecular weight, can be obtained by FAB ionization. High-mass negative ions [M - 15], [M - 60], and [M - 86] also indicate the molecular weight of the intact GPCho molecular species in somewhat less abundant yields. However, the negative FAB mass spectrum also contains intense carboxylate anions that correspond to the esterified fatty acyl groups in the phospholipid molecular species. As suggested by others $[12,13]$ and further confirmed by this report, the position of the fatty acyl groups on the glycerol backbone can be readily determined by the use of negative FAB with MS/MS. Tandem mass spectrometry also eliminates the need to carry out reverse-phase separa-
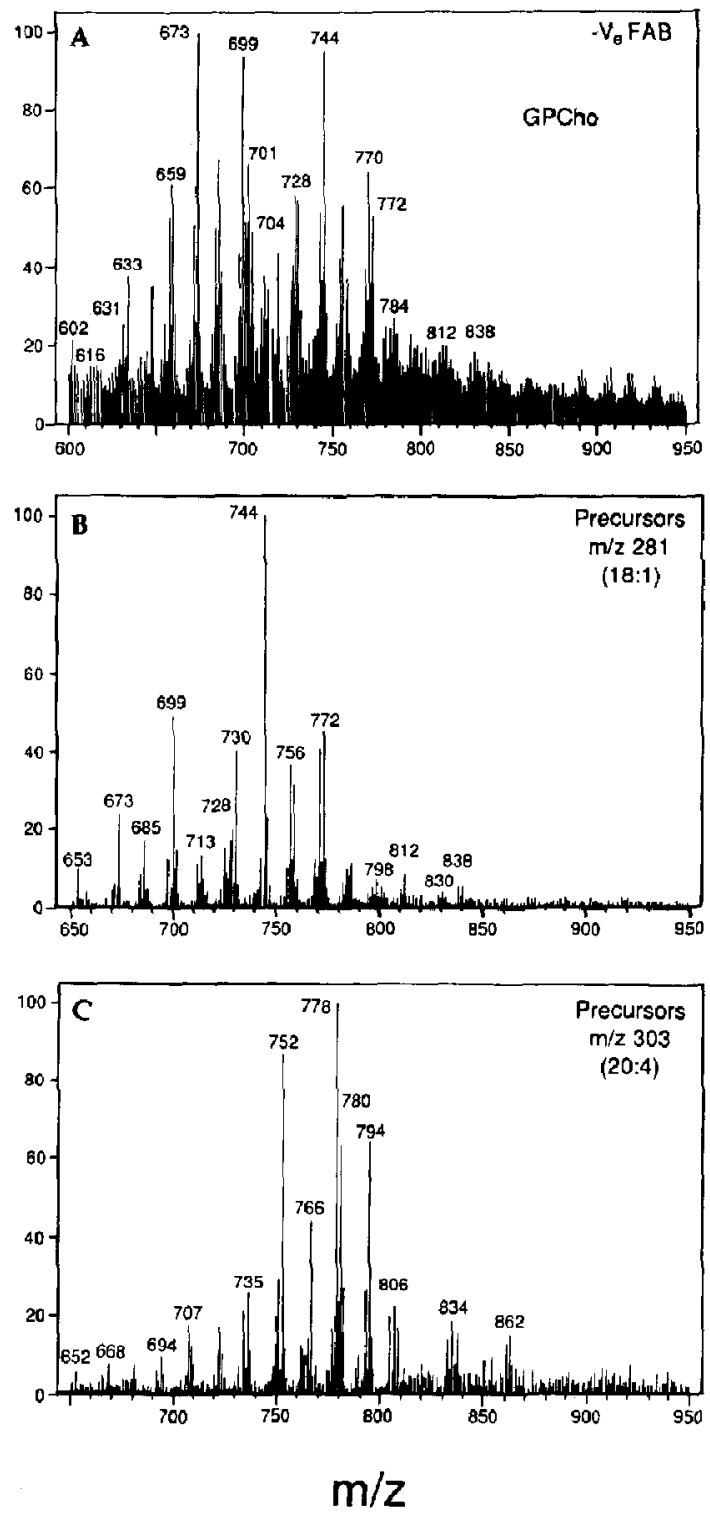

tion of individual molecular species, because the first mass spectrometer sector, either a quadrupole or magnetic sector instrument, can separate phospholipid molecular species through specific, characteristic ions. Therefore, the qualitative analysis of phospholipid molecular species is quite feasible by FAB/MS/MS.

Collision-induced dissociation of the high-mass negative ions results in the formation of carboxylate anions in abundance depending upon the site of es. terification. The anions from fatty acyl moiety at $s n-2$ are approximately three times more abundant than that from the $s n-1$ carboxylate anion. The reports published so far are consistent with this obser- 

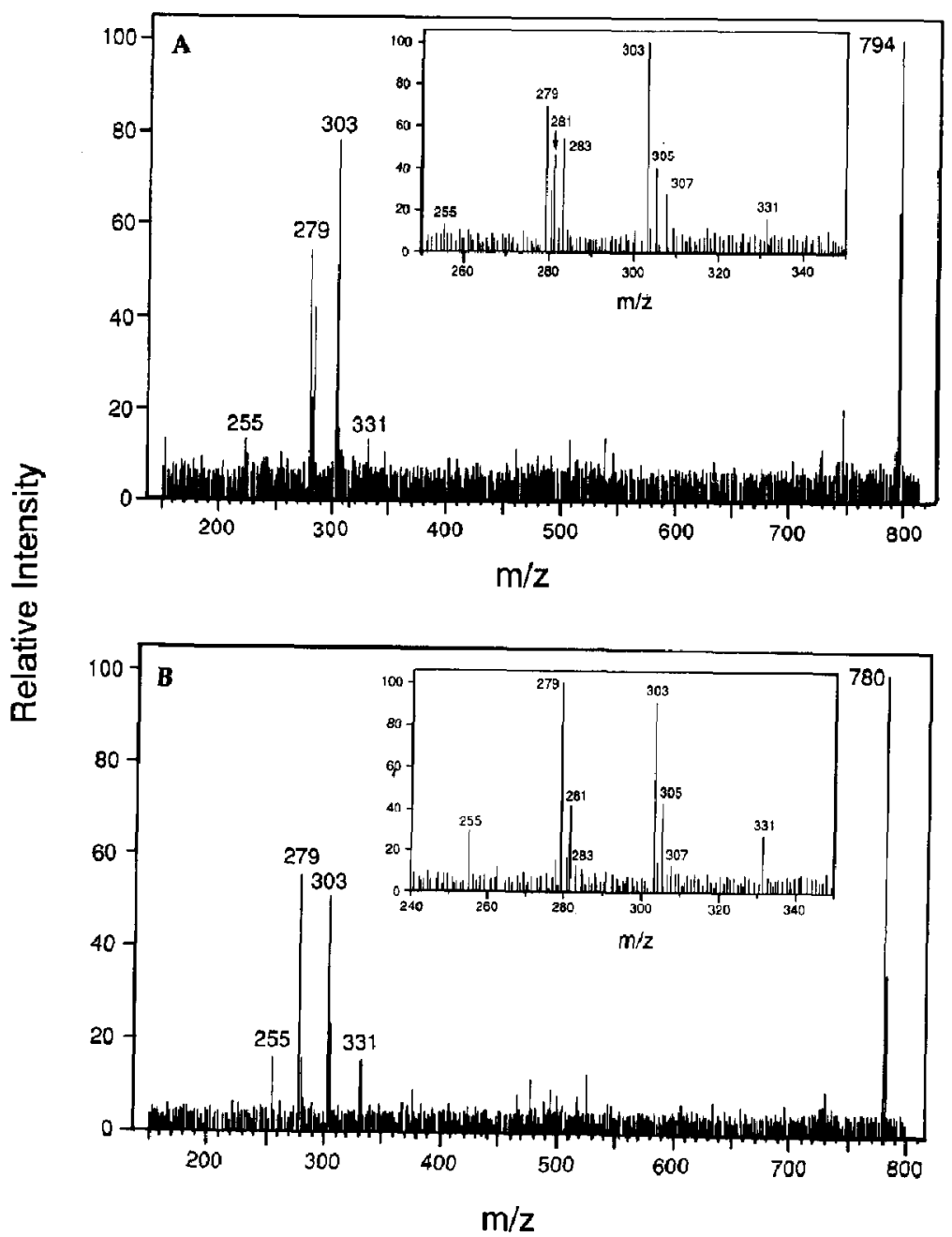

Figure 5. Product ion scans for two major precursor ions of $m / z 303$ found in the GPCho fraction from human neutrophils. (a) $m / z 794$, corresponding to 1-octadecanoy1-2-arach idonoyl-s $n$ glycerophosphatidylcholine. Other carboxylate anions correspond to isobaric molecular speries (see text). (b) $m / z 780$, corresponding to 1-O-octadecyl-2. arachidonoyl-sn-GPCho. Carboxylate anions for other molecular species are present from other isobaric molecular species (see text).

vation except for the case where the group at $s n-2$ is quite small, for example acetate, in which case a weaker signal for $m / z 59$ has been reported [13]. One suggestion for the abundant formation of $s n-2$ anion has been the release of steric strain in the decomposition mechanism while the $s n-1$ anion is being formed by an $s n_{i}$ mechanism that involves the phosphate oxygen displacing the carboxylate anion [13]. We would like to suggest that there may be many mechanisms responsible for the observed $s n-2: s n-$ 1 anion ratios and therefore a slope for the correlation time in Figure 2 different from unity. An alternative process could involve competition for the phosphate oxygen attacking either at $s n-1$ or $s n-2$, forming a six-membered cyclic transition state or five-membered cyclic transition state, with the five-membered cyclic transition state being highly favored. This would increase the abundance of the carboxylate anion arising from $s n-2$ (five-membered cyclic phosphate ester) relative to the anion from $s n-1$ (six-membered cyclic phosphate ester).
We have found that the observed ratio of the abundances of $s n-1: s n-2$ is 1:3 by this low-energy CID process for a variety of diacyl-GICho molecular species, including some containing esterified arachidonic acid. An observed deviation from this ratio suggests the presence of a mixture of molecular species, even positional isomers. The linear correlation found for the ratio of the $s n-1: s n-2$ abundances relative to PLA $_{2}$ analysis supports the idea that collisional activation of $[\mathrm{M}-15]^{-}$as well as $[\mathrm{M}-60]^{-}$anions can provide a key piece of information that permits analysis of the complex mixture of GPCho molecular species found in biological extracts. However, the lack of complete agreement for these two measurements argues for several mechanisms operating in the formation of carboxylate anions by collisional activation.

The results of the analysis of GPCho molecular species from human neutrophils containing arachidonic acid by FAB/MS/MS compare favorably with those obtained by traditional and more laborious tech- 
Table 3. Comparison of identification of GPCho molecular species containing esterified arachidonic acid, in human neutrophils

\begin{tabular}{|c|c|c|c|}
\hline \multicolumn{2}{|c|}{$\begin{array}{l}\text { Human neutrophil } \\
\text { GPCho molecular species }\end{array}$} & \multirow[b]{2}{*}{ Precursors of $\mathrm{m} / \mathrm{z} 303^{b}$} & \multirow{2}{*}{$\begin{array}{l}\% \text { Relative abundance of } \\
\text { precursors of } \mathrm{m} / \mathrm{z} 303\end{array}$} \\
\hline Literature & $\mathrm{FAB} / \mathrm{CID}^{\mathrm{b}}$ & & \\
\hline $18: 0 a / 20: 4$ & $18: 0 a / 20: 4$ & 794 & 64 \\
\hline $18: 1 \mathrm{a} / 20: 4$ & $18: 1 \mathrm{a} / 20: 4$ & 792 & 27 \\
\hline 18:0e/20:4 & $18: 0 e / 20: 4$ & 780 & 62 \\
\hline $18: 1 e / 20: 4$ & $18: 1 e / 20: 4^{c}$ & 778 & 100 \\
\hline \multicolumn{4}{|l|}{$18: 0 p / 20: 4$} \\
\hline $16: 0 a / 20: 4$ & $16: 0 a / 20: 4$ & 766 & 44 \\
\hline $16: 0 \mathrm{e} / 20: 4$ & $16: 0$ e/20:4 & 752 & 86 \\
\hline \multirow[t]{4}{*}{$16: 0 p / 20: 4$} & $16: 0 p / 20: 4$ & 750 & 30 \\
\hline & $20: 1 e / 20: 4^{d}$ & 806 & 22 \\
\hline & $20: 0 \mathrm{e} / 20: 4$ & 808 & 16 \\
\hline & $22: 1 e / 20: 4^{d}$ & 834 & 18 \\
\hline
\end{tabular}

Identified by RP.HPLC separation and FAB/MS [20, 21].

b Identified from precursor ion scan using negative FAB/MS/MS shown in Figure 4c.

'Assignment of double-bond position in the alkyl group at sn - 1 is not possible with MS/MS. These species may be plasmalogens, and both have been described in the literature [20, 21 ].

${ }^{d}$ Assignment of double-bond position in the alkyl group at sn - 1 is not possible with MS/MS.

niques including normal-phase and reverse-phase chromatographic separations and partial degradation. The eight major arachidonate-containing molecular species were readily detected, including both diacyl and alkyl ether subclasses. In addition, other minor molecular species not previously characterized could be detected. Although this approach has been illustrated with identification of arachidonate-containing molecular species, it is, of course, possible to screen for any other fatty acyl group present in the complex phospholipid mixture. Furthermore, precursor scans permit the determination of relative abundances of those molecular species that contain arachidonic acid, which is difficult to assign except by quantitative analysis of the arachidonate content following separation of each molecular species.

\section{Acknowledgments}

This work was supported, in part, by a grant from the National Institutes of Health (HL34303). We wish to acknowledge the dedicated assistance of Ms. Deborah Beckworth in the preparation of this manuscript and the technical assistance of $\mathrm{Mr}$. Charles Lewis.

\section{References}

1. Vance; D. E., Vance, J. E., Eds. Biochemistry of Lipids and Membranes; Benjamin/Cummings: California, 1985.

2. Small, D. M. In Handbook of Lipid Research; Hanahan, D. J., Ed.; Plenum: New York, 1986; vol. 4.

3. Siloius, J. R. In Lipid-Protein Interaction; Jost, P. C; and Griffith, O. H., Eds.; Wiley: New York, 1982; Vol. 2, Chapter 7.

4. Murphy, R. C.; Henson, P. M. Ann. l'Inst. Pasteur/Immunol. 1985, 136D, 175-228.

5. Burn, P. Trends Biochem. Sci. 1988, 13, 79-83.

6. Berridge, M. J.; Jrvine, R. F. Nature 1989, 341, 197-205.
7. Samuelsson, B.; Goldyne, M.; Granstrom, E.; Hamberg, M.; Hammarstrom, S.; Malmsten, C. Ann. Rev. Biochem. 1978, 42, 997-1029.

8. Murphy, R. C. In Prostaglandins in Clinical Practice; Watkins, W. D.; Peterson, M. B.; Fletcher, J. R., Eds.; Raven: New York, 1989, p 1.

9. Braquet, P; Touqui, L.; Shen, T. Y.; Vargaftig, B. B. Pharmacol. Rev. 1987, 39, 97-146.

10. Nishizuka, Y. Nature 1988, 334, 661-665.

11. Chilton, F. H.; Murphy, R. C. J. Biol. Chem. 1986, 261, 7771-7777.

12. Jensen, N. J.; Tomer, K. B.; Gross, M. L. Lipids 1986, 21 , 580-588.

13. Munster, H.; Budzikiewicz, H. Biol. Chem. Hoppe-Seyler 1988, 369, 303-308.

14. Christie, W. W. Gas Chromatography and Lipids: A Practical Guide; The Oily Press: Scotland, 1989; p 128.

15. Haslett, C.; Guthrle, L. A.; Kopaniak, M. M.; Johnston, R. B.; Henson, P. M. Am. J. Pathol. 1985, 119, $101-110$.

16. Bligh, E. G.; Dyer, W. J. Can. J. Biochem. Physiol. 1959, 37, 911-917.

17. Zirrolli, J. A.; Clay, K. C.; Murphy, R. C. Lipids in press.

18. Waite, M. In Handbook of Lipid Research; Hanahan, D. I., Ed.; Plenum: New York, 1987; Vol. 5, p 155.

19. MacDonald, J. I. S.; Sprecher, H. J. Biol. Chem. 1989, 264, 17718-17726.

20. Chilton, F. H.; Murphy, R. C. Prostaglan. Leukotr. Med. 1986, 23, 141-148.

21. Murphy, R. C.; Chilton, F. H.; Haroldsen, P. E. In Proceedings of the AOCS Short Course on Polyunsaturated Fatty Acids; Lands, W. E. M., Ed.; American Oil Chemists' Society: Chicago, Ill., 1987; Chapter 21, p 169.

22. Patton, G. M.; Fasulo, J. M.; Robins, S. J. J. Lipid Res, 1982, 23, 190-196.

23. Blank, M. L.; Robinson, M.; Fitzgerald, V.; Snyder, F. J. Chromatogr. 1984, 298, 473-482.

24. Clay, K. C. In Methods in Enzymology; Murphy, R. C.; Hitzpatrick, F. A.; Eds.; Academic: New York, 1990; Vol. 187, p. 134.

25. Haroldsen, P. E.; Voelkel, N. F.; Henson, J. E.; Henson, P. M.; Murphy, R. C. J. Clin. Invest. 1987, 79, 1860-1867.

26. Kim, H. Y.; Salem, N. Anal. Chem. 1986, 58, 9-14. 